\title{
Linguistic and Pragmatic Failure of Arab Learners in Direct Polite Requests and Invitations: A Cross-cultural Study
}

\author{
Nahed Ghazzoul \\ Dept. of English, Faculty of Arts, Al-Zaytoonah University, PO Box 130, Amman, Jordan
}

\begin{abstract}
In a cross-cultural context, the speakers' cultural disposition, linguistic codes, and social identity may influence their pragmatic behaviour; thus, lead to communication breakdowns. This paper studies the cross-cultural pragmatic failure in polite requests among Arab participants from different cultural backgrounds, and reattempts to test[ validate] the universality of Speech Act Theory, and Theory of Politeness. To that end, 96 situations have been collected from 16 Arab participants divided into two groups to examine the polite strategies they use in request and invitation situations. The results of the qualitative data analysis have shown that almost all participants favour conventionally direct strategies in requests and invitations to express politeness and hospitality. As for the Arab students who are UK citizens, the results indicated that they have a tendency to use more indirect strategies in different situations. However, this indirectness was perceived as lack of hospitality in invitations, and lack of pragmatic clarity in requests by the first group. The results of the data analysis show that there is no one formula of how politeness can be perceived by different cultures, and that the differences stem out from different socio-cultural norms. The findings also provide worthwhile insights into theoretical issues concerning Arabic communicative acts, as well as the relation between the universal pragmatic features, and culture-specific theoretical differences.
\end{abstract}

Index Terms-Arabic speech act, requests, invitations, cross-cultural communication, politeness, pragmatic failure

\section{INTRODUCTION}

People communicate when they meet together and share views, or exchange ideas. They try to ask questions, talk about things, and convince each other of their own way of thinking (Peeters, 2009, p. 60). The speaker tries to make himself understood, and the listener puts efforts into finding the meaning. In the quest for meaning, possible problems may arise either in endolingual or exolingual situations (p. 60). Endolingual refers to the communication between two people of the same native languages, who belong to the same culture, and communicate in their first language. Exolingual, on the other hand, refers to communication situations where two speakers communicate in the native language of one of them, but do not share the same culture, or native language, such as when a native speaker of English addresses a native speaker of Arabic in English. In such a situation, possible misunderstanding and problems may occur due to the differences in the cultural background between the speaker and the listener.

This study argues that the concept of indirectness and the issue of politeness play a decisive role in the realization of requests and invitations. The two concepts do not represent parallel directions, as indirectness does not always lead to politeness, especially in cross-cultural context where the speakers' cultural disposition, and social identity may influence their pragmatic behaviour. Therefore, this study examines the influence of directness in requests and invitations on the level of politeness, consequently retests the applicability of the Theory of Politeness, and Speech Act Theory in different cultural contexts.

\section{THEORETICAL ORIENTATIONS}

The two major factors in pragmatic rules are pragmatic clarity and politeness. They have been claimed to be complementary elements (Lakoff, 1973), where politeness is the motivation for indirectness in requests or invitations (Searle, 1969, 1976; Lakoff, 1973, 1989; Leech, 1983; Brown, and Levinson, 1987; Brown, 2008). Originally, linguistic philosophers such as Austin (1962), Searle (1969), and Grice (1975) were influenced by "the study of language as a social action, reflected in speech-act theory, and the formulation of conversational maxims", (McCarthy, 1991, p. 50). Speech Act Theory has been central to many studies on politeness and directness. Requests, complaints, compliments, thanks, invitations, and apologies are among the most cross-culturally investigated speech acts. The emphasis of Speech Act Theory is on what the utterer means by his/her utterance rather than what the utterance means in the language.

The theory was developed by Austin (1962) and Searle (1969). The basic belief was that language is used to perform actions: so its fundamental focus is on how meaning and actions are related to language (Schiffrin, 1994, p. 49). In his posthumous work How to do things with words, Austin (1962) introduces the notion of speech act. By it he means that "the actions performed in saying something" (p. 12). His main concern is to distinguish between two types of statements: 
constatives and performatives. By the former he means sentences/verbs describing or reporting some facts or state of affairs and deciding whether they are "true" or "false" such as saying "the cat is on the mat" or "I apologize" rather than doing and achieving something. By the latter, he means sentences, which by saying them, we are "doing something as opposed to just saying something". These sentences are "happy or unhappy as opposed to "true" or "false", (p. 133).

Later on, Austin (1962) makes a further revision when he proceeds to distinguish between three types of speech act. A speaker, in issuing an utterance, can execute three acts simultaneously: a locutionary act which refers to the actual uttering of the words with a particular meaning; an illocutionary act that means the realization of what is the speaker's intention by uttering the words, and a perlocutionary act which indicates what we often say, and it produces certain substantial effects upon the thoughts, feelings, or actions of the audience, or the speaker. A perlocutionary effect, according to Cutting (2002), takes place when we know exactly what is done by uttering these words, and what is their real effect on the hearer. However, one can normally perform all three types of speech acts simultaneously, "but it is useful for analytic purposes to isolate them" (Coulthard 1975, p.18).

The above discussion underlines the centrality of the illocutionary force in understanding the functions of language. Austin argues that despite the useful distinction between illocutionary and perlocutionary acts, the functions of language are to be recognized only with the illocutionary acts, so he referred "to the doctrine of the different types of function of language ... in question as the doctrine of illocutionary forces" (Austin 1962: 99). Accordingly, he abandoned his original distinction between performatives and constatives, and realised that implicit performatives do not always have explicit and clear performatives, so when we say "I' ll be back!" it can mean that either "I promise I'll be back, so wait for me", or "I warn you that I'll be back, so better you leave". Therefore, Austin adopts new classifications or "programmes" as he calls them the families of acts. They are organized according to their illocutionary force.

However, the classification of the illocutionary acts does not cover all our utterances. For example, an utterance like 'I declare to you my fault', cannot be false or true. It is rather an utterance that should meet certain felicity conditions, and it is considered wrong if the speakers are not in a condition to confess, or they are drunk and not aware of what they are saying; or if the hearer does not believe that the speaker is serious... etc. The speaker does not fulfill the confession if the actual appropriate context for the act does not function properly.

Addressing this gap in the theory, Searle (1969) develops Austin's theory and suggests the "functional model". At the beginning, he criticises Austin for the "persistent confusion between verbs and acts" because not all verbs are illocutionary verbs. He also adds that "there is too much overlap of the categories; many of the verbs listed in the categories don't satisfy the definition given....and, most important, there is no consistent principles of classification" (Austin, 1962, p.354). Despite the major differences between the two writers, there is one point of agreement between them which relates to abandoning the idea of the perlocutionary act, and concentrating on the illocutionary act.

Furthermore, Searle (1968) considered speech act as the basic unit of communication, so this view places speech acts at the very crux of the study of the language, communication, and meaning, and brings the speech act rules to be part of linguistic competence. His principle of expressibility brings the study of speech acts, meaning, language, and communication together. He further considers that "the meaning uniquely determines a particular force, these are not two different acts, but two different labels for the same act" (p. 407).

Meanwhile, in an attempt to find a solution to the classification of speech act, Searle $(1969$, p.13) identifies five macro-classes that include: Representatives, Directives, Expressives, Commissives and Declaratives. The last category includes words that change the world by their utterances, such as 'I bet', 'I resign', 'this court sentences you to ten years imprisonment', or when the authorized person says: "I baptised this boy John Brown' which changes a nameless baby into one with a name. Also, when it is said 'I hereby pronounce you man and wife' to change their status from being single to a married couple. This category is equal to Austin's performatives where it requires the power of a certain institution, or authority to be valid. Leech (1983); however, argues that the declaratives "are not illocutionary acts at all, instead, they are conventional rather than communicative acts: the linguistic parts of rituals" (p.180). Finally, Searle (1969) recognizes a general condition for all speech acts, this condition is based on the speaker-hearer relationship where the speaker must be clear, sincere, and not pretending or playing an act; simultaneously, the hearer must hear and understand the language, and if there are any gaps in this equation, the process of speech act is incomplete.

Speech act theory has been criticised for attempting to capture all the possible functions of the language by classifying the kind of actions that can be performed by speech. Wierzbicka (1985) accuses Searle of regarding the differences in indirect speech forms from one language to another as random and accidental, while holding the view that the general mechanisms of speech acts are universal. She tries to prove that the mechanisms of the theory of speech acts are culture-specific, and the variations are motivated by different cultural norms. Nobody can deny the useful contribution that Austin, Searle, Grice and others made, but they are subject to criticism because their generalizations are not absolute. The theory has also been criticized because of the "impossibility of assigning a single force to an utterance" (Leech \& Thomas, 1990, p.196), or to use Allan's (1998) terms the difficulty of "pinning down" (p. 933) the illocutionary intention of the speaker. An utterance may have more than one function, and a function may be expressed in different forms or even in a lengthy discourse, or fall into more than one macro-class.

Although Speech Act classification is helpful, it cannot embrace all the tiny cultural specifications in all societies. What is assumed to be widely universal, are the acts of making statements, asking questions, and issuing commands. The questions to be asked are: to what extent the issues of indirectness are universally applicable to all cultures 
following the speech act theory? To what extent the issues of directness can influence the level of politeness in two different languages such as Arabic and English?

\section{A. Speech Acts in Arabic: Cross-language Studies}

Arabic is everyday speech of most inhabitants of the Middle East and North Africa. Two forms of Arabic are the medium of communication in these regions: standard and spoken Arabic. Classical Arabic (standard) is the language of Koran and other written materials. Arabic speech acts provide their users with means of constructing statements, questions and commands. For example, declaratives may have obligatory forms, and may be used to ask questions, while interrogatives can be used to state propositions. Imperatives, on the other hand, are used to direct attention, give a command, show kindness, and finally offer and extend invitations. It is important to note that the Arabic statements and questions have the same word order. If Arabic question particles are deleted, the question can be formed by intonation only. Applying this rule to English could be a point of difficulty for learners because English language forms questions and interrogatives in completely different word orders. Changing this word order can cause syntactic failure to question or interrogative forms. On the other hand, Arabic Expressives, Commissives, Directives and Representatives perform almost the same illocutionary acts as in English. Declaratives and Directives are related to issues of directness and matters of politeness.

Nonetheless, Arabic and English illocutionary acts differ not only in their functions, but also in their degree of politeness and committing oneself to it. Cultural and ritual influences govern the level of politeness in the Arab World in general. For instance, it is not always preferable to compliment somebody's belongings because it will be understood as an indirect request on the part of the speaker to make the hearer say "moqadam" (it is a present for you), so, not praising in this situation is not out of rudeness, but out of respect of the cultural rules of the society. A pragmatic failure can happen in such situations. Also, the ritual belief in the "evil eye" is a point of dispute in comparison between English and Arabic strategy of politeness. Arabs believe that if praising directly someone's appearance, fitness, or physical power... etc, without saying "masha"a al-lah, or yikhzi al-3een" (If God's will, or evil eye gets blinded), the hearer will feel that something wrong may happen to him/her.

The idea of clarity is related to the idea of directness in Arabic as in making someone come to the point directly. For example, in marriage proposals, it is a merit for men proposing to be direct and sincere. In general, the actual act of proposing is a social interaction that is essential preliminary to marriage itself. Such illocutions have the effect of getting the hearer (the girl) to marry the speaker (the man), when asking for her hand from her father or guardian as in saying: I am honoured to ask for your daughter's hand. Unlike Christian rituals of marriage where the two partners attend physically, and repeat what the priest says, the marriage procedures in Arab Islamic culture do not necessarily require the presence of the partners or pronouncing the locutionary words allowing the illocutionary action to take place. For instance, if the couple are present to fulfill the official marriage and the bride is being asked if she accepts this man to be her wedding husband, she can answer "yes" and it is necessary for the answer to be heard if she has married before, or she can keep silent if she is virgin. In the later case, her silence is taken as an indication of acceptance; consequently the perlocutionary action will take place. Silence is a polite strategy that can be followed by oriental women to express approval especially when the subject is socially embarrassing such as marriage, love and sex. Such cultural differences create not only a pragmatic failure, but they also validate an action that can be invalid somewhere else. The "yes" answer, or the non-verbal answer means in Christianity and in Austin's terms the failure of the procedure.

Similarly, the verbal action of divorcing the partner can happen among Muslims and the utterance itself in certain conditions can validate the procedure of divorce. To execute divorce in Islam, men and rarely women should utter certain words: "enti talek", "you are divorced", meaning "I herby divorce you" three times consecutively to actually divorce their wives/husbands. If these words are said only once or twice, the divorce is not fulfilled or performed. The Holy words of Koran and Muslim beliefs specify these conditions to be met. It is important that the procedure meets the thoughts, intentions and feelings already specified for it. Again, cross-cultural differences create a pragmatic failure because uttering the words alone is sufficient for the three levels of the speech act to take place. According to Levinson (1987), it is infelicitous in an English society to perform divorce merely by uttering "I hereby divorce you" because this is not a conventional procedure that has conventional effect ( $p, 229)$.

Finally, Arabs tend to use lengthy expressions in repaying compliments. The word "shukran" (thank you) is not a sufficient response to Arabic compliments and needs to be supplemented by additional words such as: I do not know how to thank you, I will never forget your favour. "By itself, it may sound flat and awkward because it appears to signal the end of the conversation", (Nelson, et al cited in Cutting, 2002, p.179). In an attempt to make their responses sound sincere in the listener's ears, learners of ESL/EFL, "use more words than a native English speaker does. This overindulgence in words may result in pragmatic failure" (Blum-Kulka and Olshtain, 1986, p. 175) because native speakers consider it as a lack of appropriateness.

\section{B. Directness and Politeness}

Lakoff (1973) could be called the mother of the modern theory of politeness. She defines politeness as "a system of interpersonal relations designed to facilitate interaction by minimizing the potential for conflict and confrontation inherent in all human interchange" (p. 34). Politeness is an essential part of pragmatics and a social value or cultural feature that might be called "urbanity" that occurs in all civilized societies House and Kasper (1981). 
Furthermore, Brown \& Levinson (1987), see politeness in terms of conflict avoidance. The central themes for them are "face" and "rationality" which are possessed by all speakers and hearers-personified in a universal "Model Person". This model has a face which means "the public self-image that every member wants to claim for himself" (p. 61). It consists of two opposing "wants": negative face and positive face. Positive face means "the want of every member that his wants be desirable to, at least, some others" (p. 62) while negative face means "the want of every "competent adult member that his actions be unimpeded by others" (p. 62). Moreover, "Face", is something that can be lost, maintained or enhanced, and because of its sensitive nature, everybody tries to keep each other's face in interaction. Adults who possess "rationality" act to maintain face.

Brown \& Levinson argue that some acts are intrinsically face threatening acts (FTAs) and speakers try to minimise the FTAs by choosing appropriate strategies. Confirming this, Brown (2008) states that face is "the underlying motivation for speakers to apply language politely...[it] ... is broadly taken to refer to images or identities (of the individual or group)" (pp.68-69). In other words, the concept of face refers to the manner in which people interact socially, thus it is used to understand meaning in social interaction, and determine the polite or impolite acts because they are embedded in the interlocutors" perception in particular contexts, Ohashi (2013). This entails that the fear of losing face may prevent people from breaking the norm of politeness. Eshreteh (2014) views face as a metaphor of politeness which "uncovers both the informational and affective dimensions of language use in structuring human relationship" (p. 81). On the other hand, Leech (1983) makes a distinction between "Absolute Politeness" and "Relative Politeness" (pp. 83-4). The former refers to a scale with a negative and a positive pole. Some acts are naturally polite like offers or invitations, and others are inherently impolite like commands or orders. So, negative politeness aims at minimizing the impoliteness of the impolite illocutions because the requests may benefit the speaker rather than the hearer, while positive politeness aims at maximizing the politeness of polite illocutions.

In retrospect, the issue of directness and its influence on the level of politeness is discussed by Searle (1976) illocutionary acts. He defines directives as "an attempt by the speaker to get the hearer to do something". This attempt can be simple as when I invite somebody to do something, or forcefully as when I insist that someone does something. Leech (1983) suggests that "directives" comprise acts of ordering, commanding, requesting, and advising. Some of these acts are intrinsically polite, such as invitations. Ervin-Tripp (1973) adds that they can be realized in different syntactic forms such as statements, interrogatives, and imperatives that reflect different degrees of politeness.

Generally speaking, English indirect speech acts constitute one of many forms of politeness. Indirectness is associated with politeness and directives are more often expressed as interrogatives than imperatives. Some of the factors that make the speakers use indirect directives are the lack of familiarity with the person or the context, or the social difference like the differences of roles, age, gender, status, education, occupation, and ethnicity. Social distance usually, gives speakers power and authority, so those who are in less dominant roles tend to be more indirect.

\section{Methodology And Data AnAlysis}

This study examines the cross-cultural linguistic and pragmatic failure in polite requests and invitations between British and Arab participants from different cultural background. It also reattempts to test the applicability of Speech Act Theory, and the Theory of Politeness. The data analysis tries to find answers to the following research questions:

Does the level of directness affect the level of politeness of Arab EFL learners?

Is Speech Act Theory applicable to all cultures?

To explore the aims of the study, a discourse completion test was prepared (see Appendix 1) for the sake of this paper. The test consisted of four open ended situations which were constructed in a way that showed the act/words which would be performed/said by the speaker. Sixteen Arab participants filled in the completion test. Eleven of them were Arab EFL students studying in the UK, and five were UK citizens, from Arab origin. The researcher explicitly told them to write what they would really say in similar life situations. Qualitative data analysis was undertaken to elicit responses to the request and invitation situations they completed. The collected responses backed up the argument about Arabic politeness and Speech Act Theory. The first part on "directness and issues of politeness" provided answers to the first question, and the second part on "speech act cross cultural issues", offered answers to the second question.

\section{FINDINGS AND DisCUSSION}

\section{A. Directness and Issues of Politeness}

The word politeness in Arabic means "Adab" and it is implied in words and deeds of people in an attempt to maintain a positive face. Many empirical studies were carried out in favour of measuring the weight of politeness in the Arab world by American researchers (Cutting, 2002), and Arab scholars (Atawna, 1991; Auty, 1996; Al-Khawaldeh, 2014; Qari, 2017). This paper refers to some of their findings and relates to the current study. This section tries to find answers to the first research question: Does the level of directness affect the level of politeness of Arab EFL learners?

Unlike English which forms polite requests by using a variety of modals and conditionals, Arabic employs imperatives, lexical items and less complex devices for performing requests. It is, for instance, very odd in Arabic to use "would you mind" to ask somebody to pass the salt from the table. Arabic language lacks the past modals and this creates a problem for EFL learners since they overuse "can" and avoid using "could" or "would". The same thing 
happens with "may" and "might" (Atawena, 1991, p. 212). Imperatives in Arabic are mitigated by using softening devices that are consistent with the nature of the language, thus words like "mumkin" (can), "iza mumkin" (If you can), "btiqder" (are you able) are the only models in Arabic. Softening the command and turning it into a request can be done by including the hearer in the activity, so the plural pronoun "we" is used to show solidarity, familiarity, closeness, and more respect on the side of the speaker, e.g: Let's have a bite. Most of the respondents to situations (3), and (4) used the pronoun "we" (We want you to have dinner with us...Join us for God's sake...Come eat with us) to invite someone for food. This strategy reflects the absence of social distance between the interlocutors, and consequently allows for terms that would give positive self-image (You are on the right time, come and eat with us.....You come in the right time). As for situations (1), and (2) most of the respondents tend to be direct, and use the imperative mode to bring the hearer to perform an action such as: Don't go alone, wait for me... We want you to have dinner with us... Open the window ... Do not go before me". However, for all the situations, it is noticeable that British participants are less direct in responding to the situations than Arab learners (can you please open the window? Can you wait for me so we can go together?... Help yourself).

These findings echo those of Qari (2017) who investigated the politeness strategies in requests and apologies used by a group of Saudi learners, EFL learners, and British citizens. She concluded that both Saudi males and females preferred to use direct strategies in their requests, while EFL and British groups were thoroughly more indirect. She added that Saudi learners used the largest number of modifiers, like prayers and religious softeners. On a closer inspection, it looks that directness as used by EFL Saudi learners does not equate impoliteness, as suggested by Brown and Levinson (1987), rather, "it might be the case that the British tend to express polite forms by using syntactic and linguistic devices; whereas the Saudis tend to express polite forms by using direct linguistic means mitigated by the use of semantic softeners" (pp. 2-3).

In general, directives in Arabic, are usually associated with imperatives that are used to show high level of politeness besides giving command. For example, when saying "eat or I will be angry", the speaker expresses a polite request; while when saying "write your homework now" he is giving a command. The word order of the normal statement in Arabic does not change when forming imperatives. In some cases, directive imperatives are preferable, especially when an invitation for more food is made. The use of indirect form can be seen in this case as a weak desire on the part of the speaker to make the hearer eat more; while in English, indirect directives can be considered more polite than direct directives. Moreover, directness in Arabic is usually associated with positive politeness, (Ferguson, 1967). So, a word like "tafadal", with the meaning of enter or help yourself is very formal and polite. The analysis of the completion test for situations (4) and (5) reveals that most of EFL learners would impose food and force the visitor to eat: "You will eat, it is not optional I swear I will be angry if you do not join me the food" (2 $2^{\text {nd }}$ Participant).

The discussion above indicates that there are differences in politeness strategies in requests and invitations between English and Arabic because of linguistic and cultural variations. The strategy of face threatening act (FTA) is used in English more than Arabic, and the strategy of silence is used in Arabic in different situations according to cultural differences more than in English. According to Brown and Levinson's model (1987), English is more polite than Arabic, while in following Leech's model, Arabic is more polite than English. Politeness is a socio-cultural linguistic phenomenon that is culture-specific therefore, the conception, and the degree of politeness "are not the same among different cultures, and thus the different perceptions on politeness may lead to misunderstandings and conflicts in intercultural interactions" (Ae Yu, 2011, p. 386).

\section{B. Speech Act: Cross-cultural Issues: Invitations and Requests}

Analysis of the situations indicates that the majority of the respondents used the words "God" and "Allah" to force the hearer to respond to their requests. The word "God" by itself has an illocutionary force in Arabic. If someone gets invited to a dinner and feels full, the host, out of politeness, asks him to eat more, and quite often swears by Al-Mighty God that the guest should eat more as we see in the responses: "I swear by Allah I will not accept your invitation next time if you do not join me. I ask you by Allah name not to refuse my invitation....Join us for God's sake ... I swear by God, you eat", because the word "God" has a religious connotation of respect and reverence, the guest usually responds positively lest he should be considered rude, or not a good believer. Others would even swear to divorce their wives as the case of the 2nd participant, "I swear to divorce my wife if you do not eat", if the hearer does not do something they ask for. This strategy is usually used to show great hospitality, but neither the speech act theory nor its levels and classifications argue about such locutionary acts, and their illocutionary forces and perlocutionary effects. Opposite to what is expected, the perlocutionary effect will take place immediately if the hearer complies to the wish of the speaker, the action of divorce will not happen, and the speaker will benefit from the situation; but if the hearer does not respond for certain reasons such as not belonging to the same culture, and does not understand what are the consequences of not responding to the speaker's words, the perlocutionary effect will take place and divorce will happen.

It is culturally normal for Arabs to show polite obliging invitations; and it is humiliating for hosts to have their repeated offers refused. Such a refusal means the demonstration of the superiority of the guest. According to the cultural norms, the hearer can be considered as following inappropriate strategy of politeness. Similarly, not complimenting someone's appearance or belongings relates to cultural and ritual differences and not to the lack of sense of politeness. 
Furthermore, to show generosity, and save the guests of face threatening acts, or not to lose their positive faces, most EFL learners suggested that when inviting friends to restaurants, they would order for them the meals, because as participants 2 and 8 mentioned "They maybe feel shy to order a lot so I order it for them. I order it for them so they will not avoid ordering expensive meals because I am paying..... I order for them because it is something cultural". However, British participants mentioned that they "would give [the guests] the freedom of choice because they would want to choose what they want to eat for themselves", or they would share ...thoughts with them, because it's the right thing to be done". If we interpret the words of the invitations of the first group linguistically, we can say that the utterer is imposing something on the hearer and this is absolutely rude. However, on the pragmatic level, the intentions of the speaker are good, and on the cultural level such behaviour indicates generosity on the part of the utterer, but neither the speech act theory nor its classifications acknowledge such locutionary acts, and their illocutionary forces, or perlocutionary effects.

Speech Acts and their linguistic realizations are the reflection of the social values of a particular culture. They are governed by rules and norms of language usage and not usually taught as a component of language to enable learners to communicate more effectively in the target language (Wilson, 1987). Therefore, ignorance of the social values, rules and norms that govern the language can cause "communication breakdown", or "pragmatic failure" (Thomas, 1983). In such cases, learners resort to their native cultural norms to determine their choice of the target language forms. They often use "negotiating strategies" (Long, 1983) in speaking with native speakers, but their choice deviates from the norm of the target language and learners may be misunderstood. Sapir (1966) states that "no two languages are ever efficiently similar to be considered as representing the same social reality" (p. 69). Due to these cultural variations, and the differences in speech act conventions, difficulties may arise. In fact, most of the differences are points of difficulty for learners in both speech act procedure and politeness strategy. Wierzbicka's (1985) objections to the English frame of speech act theory seem logical because different cultures generate different speech acts. From an English speaker's view, the Arabic way of speaking and communicating is sentimental, superstitious and reflects a lack of consideration. From an Arab point of view, the English way of speaking may be seen as reflecting a lack of warmth, a lack of spontaneity, and a lack of directness.

As such, Speech Act Theory is not the title that labels all our utterances for its limited capability in analysing conversations because speech acts are usually defined in terms of speaker's intentions and beliefs. The nature of the conversation depends crucially on the cross-cultural interaction between the speaker and the hearer. In order to practice speech acts that are useful for both the speaker and the hearer without risks of pragmatic failure, new methods and approaches have to be elaborated, and new models have to be found. These models may enable us to gain more insight into the people's internal processes while they are thinking and communicating. We need to know more about how people think in different cultures; to free the theory of Speech Act from its Anglo-American base, and to present a truly cross-cultural general theory.

\section{CONCLUSION}

This paper discussed the cross-cultural pragmatic failure and miscommunications that occur when EFL Arab students use direct requests or invitations with British friends. It also considered the issues of directness and their influence on the level of politeness that is conveyed in two languages: English and Arabic. The results of the data analysis indicate that the differences between the systems of the two languages, English and Arabic besides the cultural differences, create inappropriate situations for learners when they invite, or are invited by someone from a different culture. Therefore, the findings revoke the claims of the universality of speech act theory, and the theory of politeness, and call for more researches in this field. EFL learners often encounter problems in cross-cultural communication; therefore, this study is potentially helpful to promote the development of new communicative approaches for teaching politeness strategies for EFL learners who rarely study theory of politeness or speech act theory in their syllabi.

\section{APPENDIX I}

\section{POLITENESS COMPLETION TEST}

Dear Participant,

Below you have four situations. In every situation you are asked to write exactly what you would say in the suggested situation.

The length of the answer may vary from one word to several sentences. Length is not important as far as the utterance/s sound natural.

It is important to note that all the responses will be treated anonymously and will be used for the sake of "Cultural and Cross-Cultural Communication" assignment.

Than you very much for your participation.

Name:.

Gender:......

Nationality:...

POLITENESS COMPLETION TEST 
What would you say in the situations below if you were in the following positions?

A. Request

Situation 1

1. You are in a dear friend"s or a relative house. You feel hot so you want your dear friend/relative to open the window. What would you say?

You would say....

Situation 2

2. You want to ask a friend to wait for you so you can go together.

You would say...

B. Invitations

Situation 3

1. You want to invite a friend for your next week party.

You would say

Situation 4

2. A friend arrives at dinner time, you want to invite him/her to join in.

You would say.

Situation 5

3. If you are having dinner with your wife/husband when a friend comes. You invite her/him to join you but s/he refuses. What would you say?

I would say.

Situation 6

4. You invite friends to a restaurant. Do you order the meal for them or you give them the freedom of choice? Why?

Thanks for your help

\section{APPENDIX II}

Transliteration

Taken from Johnstone (1991) and modified by me

\begin{tabular}{|c|c|}
\hline English Letters & Arabic Letters \\
\hline $\mathbf{a}$ & $i$ \\
\hline b & ب ب \\
\hline $\mathbf{t}$ & ت \\
\hline$\theta$ & ث \\
\hline $\mathbf{j}$ & ج \\
\hline h & $\tau$ \\
\hline kh & $\dot{\tau}$ \\
\hline d & I \\
\hline б & $\dot{j}$ \\
\hline $\mathbf{r}$ & J \\
\hline $\mathbf{z}$ & j \\
\hline $\mathbf{s}$ & 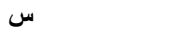 \\
\hline sh & ش ش \\
\hline Ş & ص \\
\hline dh & 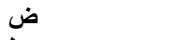 \\
\hline ta & b \\
\hline ðа & ظ \\
\hline 3 & $\varepsilon$ \\
\hline gh & $\dot{\varepsilon}$ \\
\hline f & ف \\
\hline q & ق \\
\hline $\mathbf{k}$ & s \\
\hline 1 & J \\
\hline $\mathbf{m}$ & p \\
\hline $\mathbf{n}$ & ن ن \\
\hline h & - \\
\hline w & 9 \\
\hline $\mathbf{y}$ & ي \\
\hline
\end{tabular}

\section{REFERENCES}

[1] Ae yu, K. (2011) "Culture-specific Concepts of Politeness: Indirectness and Politeness in English, Hebrew, and Korean Requests", Intercultural Pragmatics 8 (3), 385-409. 
[2] Al-Khawaldeh, N. (2014). Politeness Orientation in the Linguistic Expression of Gratitude in Jordan and England: A Comparative Cross Cultural Study. Unpublished PhD. UK: University of Bedfordshire.

[3] Allan, K. (1998). Meaning and Speech Acts. Monash University: http://users.monash.edu.au/ kallan/papers _/Speechacts.html. (accessed: 6/2/2018).

[4] Atawneh, A.M. (1991). "Politeness Theory and the Directive Speech Act, in Arabic-English Bilinguals: An Empirical Study". Unpublished PhD Dissertation. New York: State University of New York.

[5] Austin, J.L. (1962). How to Do Things with Words. Cambridge, Mass: Harvard University Press.

[6] Auty, N. (1996). Politeness Strategies in Arabic and English: A Contrastive Study of a Formal Domain. Unpublished MA. Thesis, Surrey: Surrey University.

[7] Blum-Kulka, S. A nd Olshtain, E. (1986). "Too many words: length of utterance and pragmatics failure", Studies in Second Language Acquisition, 8 (2), 165-79.

[8] Brown, L. (2008). The Korean Honorifics System and Politeness in Second Language Learning. Unpublished Ph.D. Dissertation. London: University of London.

[9] Brown, P. \& Levinson, S.C. (1987). Politeness: Some Universals in Language Usage. $2^{\text {nd }}$ edition, Cambridge: Cambridge University Press.

[10] Coulmas, F. (Ed) (1981). Conversational Routines. La Hague: Mouton.

[11] Coultard, M. (1975). An Introduction to Discourse Analysis. $2^{\text {nd }}$ edition, London: Longman.

[12] Cutting, J. (2002). Pragmatics \& Discourse. London \& New York: Rutledge.

[13] Ervin-Tripp, S. (1973). Language Acquisition and Communication Choice. Stanford, California: Stanford University Press.

[14] Eshreteh, M. (2014). A Cross-cultural Socio-pragmatic Study of Invitations in Palestinian Arabic and American English. Unpublished Ph.D Dissertation, Universidad Complutense de Madrid, Madrid.

[15] Ferguson, C. (1967). "Root-echo Responses in Syrian Politeness Formulae", in Stuart, D.(ed.) Linguistic Studies in Memory of Richard Stade Harrel, Georgetown University Press, pp. 37-45.

[16] Grice, H. P. (1975). "Logic and Conversation". In Cole, P. and Morgan, J.L. (eds.) Speech Acts: Syntax and Semantics3. New York: Academic Press, (pp. 41-58).

[17] House, J. and Kasper, G. (1981). "Politeness Markers in English and German". In Coulmas, F. (ed.), Conversational Routine: Explorations in Standardized Communication Situations and Prepatterned Speech. The Netherlands: Mouton Publishers, (pp. 157-185).

[18] Lakoff, R. (1973). "The Logic of Politeness; or, Minding Your P"s and Q"s". Papers from the Ninth Regional Meeting of the Chicago Linguistics Society. Vol. 9, pp. 292-305. Chicago.

[19] Lakoff, R. (1989). “The Limits of Politeness: Therapeutic and Courtroom Discourse”, Multilingua, 8, 101-129.

[20] Leech, G. (1983). Principles of pragmatics. London: Longman.

[21] Leech, G., \& Thomas, J. (1990). "Language, Meaning and Context: Pragmatics". In N. Collinge (Ed.), An Encyclopedia of Language. London: Routledge.

[22] Levinson, S.C. (1987). Pragmatics. Cambridge: Cambridge University Press.

[23] Long, M. H. (1983). "Native Speaker/Non-Native Speaker Conversation and the Negotiation of Comprehensible Input", Applied Linguistics, 4(2), pp. 126-141.

[24] Lyons, J. (1981). Language, Meaning \& Context. Glasgow: Fontana/Collins.

[25] McCarthy, M. (1991). Discourse Analysis for Language Teachers. Cambridge: Cambridge University Press.

[26] Ohashi, J. (2013). Thanking and Politeness in Japanese: Balancing Acts in Interaction. Basingstoke: Palgrave Macmillan.

[27] Peeters, B. (2009). Language and Cultural Values: The Ethnolinguistic Pathways Model. FULGOR, 4(1). pp. 59-73.

[28] Qari, I. (2017). Politeness Study of Requests and Apologies as Produced by Saudi Hijazi, EFL Learners, and British English University Students. Unpublished PhD. London: University of Roehampton.

[29] Sapir, E (1966). Culture Language and Personality. US: University of California at Berkeley.

[30] Schiffrin, D. (1994). Approaches to Discourse. Oxford: Blackwell.

[31] Searle, J.R. (1969). Speech Acts. Cambridge: Cambridge University Press.

[32] Searle, J.R. (1976). "A Classification of Illocutionary Acts", in Language in Society, vol. 5(1), pp. 1-23.

[33] Thomas, J. (1983). "Cross Culture Pragmatic Failure”, Applied Linguistics, 4(2), pp. 91-112.

[34] Watt, R.J. (2003). Politeness. Cambridge: Cambridge University Press.

[35] Wilson, J. (1987). Negotiation and Breakdown in Speech Event Construction. In Reilly, R.G.(ed.)(1987) Communication failure in dialogue and discourse detection and repair processes. New York: Elsevier Science Publishing Company. INC.

[36] Wierzbicka, A. (1985). "Different Cultures, Different Languages, Different Speech acts", Journal of Pragmatics, 9(2-3), pp. 145-187.

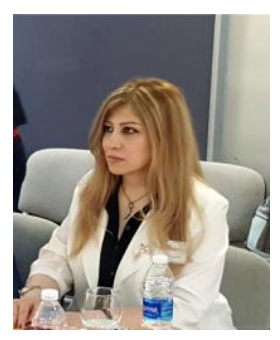

Nahed Ghazzoul is an Assistant Professor at Al- Zaytoonah University/Jordan. She is a Syrian academic who moved to work in Jordan during the Syrian Crisis. She holds PhD in Linguistics/Lancaster University (2008), Certificate in Learning and Teaching in Higher Education/Lancaster University (2005), MA in Linguistics (TESOL)/Surrey University (2003). English academic writing, Linguistics, Translation, E-learning and Sociolinguistics are her field of expertise. Her research papers have been published in international Journals indexed in: Thomson Reuters, SCUPOS, ERA and EBESCO. 